\title{
REALIDADE VIRTUAL COMO FERRAMENTA DE SENSIBILIZAÇÃO DO PÚBLICO NA CONSERVAÇÃO DA BIODIVERSIDADE MARINHA
}

Ana Julieta Ratzka Guedes Santos ${ }^{1}$ Denis Moledo de Souza Abessa²

Resumo: Esta pesquisa avaliou o uso de óculos de realidade virtual (VR) para envolver o público na conservação marinha, verificando sua eficiência a partir da análise da percepção dos indivíduos sobre aspectos do ambiente marinho e da conservação da biodiversidade marinha. Foram entrevistadas oitenta pessoas, por meio de dois questionários, realizados antes e depois da exibição de vídeos com auxílio dos óculos de VR. As reações do público foram bastante positivas, e conclui-se que a VR pode ser uma importante ferramenta para a educação ambiental, estimulando a sensibilização e as mudanças de atitudes do público em relação à conservação marinha, com implicações positivas sobre o ambiente e a sociedade.

Palavras-chave: Realidade Virtual; Educação Ambiental; Conservação Marinha.

Abstract: This investigation assessed the use of virtual reality glasses (VR) as a tool to involve the public in marine conservation, verifying its effectiveness from the analysis of the perception of individuals about aspects of the marine environment and the conservation of marine biodiversity. Eighty people were interviewed, using two questionnaires, before and after the exhibition of videos using the VR glasses. The reactions of the public were very positive, and we concluded that VR may be important tool for environmental education, stimulating changes of attitude and public involvement for the marine conservation, with positive implications to the environment and society.

Keywords: Virtual reality; Environmental education; Marine Conservation.

${ }^{1}$ Universidade Estadual Paulista - UNESP. E-mail: julieta.ratzka@yahoo.com

2 Universidade Estadual Paulista - UNESP. E-mail: denis.abessa@unesp.br

http://lattes.cnpq.br/2842419319556542

Revbea, São Paulo, V.16, № 5: 46-73, 2021. 


\section{Introdução}

Atualmente, o mundo atravessa uma grave crise ambiental, na qual o ambiente vem experimentando um cenário de rápida degradação e a capacidade de suporte dos ecossistemas terrestres e aquáticos já se encontra no limite ou ultrapassada (WWF, 2019). Ainda segundo estes autores, (WWF, 2019), em aproximadamente meio ano, o ser humano utiliza mais recursos naturais do que o planeta pode regenerar em um período de 12 meses. Essa crise, no Brasil, envolve questões como o aumento do desmatamento, a inibição e tentativa de criminalização dos órgãos de fiscalização, como IBAMA e ICMBio, a expansão das atividades agropecuárias sobre áreas protegidas e territórios indigenas, a poluição dos recursos hídricos por lixo, esgoto sanitário e efluentes industriais, as mudanças climáticas, o corte dos recursos destinados a fiscalização, e muitos outros fatores que afetam o ambiente e, direta ou indiretamente, população em geral (ABESSA et al., 2019).

Diante desse cenário preocupante referente à degradação ambiental e esgotamento dos recursos naturais, surge também uma preocupação com os ecossistemas marinhos e costeiros. Oceanos e áreas costeiras, como os estuários, vêm sendo ameaçados pelas ações humanas, sofrendo impactos cumulativos destas atividades, tanto na forma de exploração direta dos recursos, como em consequência de agentes poluidores, degradação física do ecossistema marinho e mudanças climáticas (FERREIRA; LACERDA, 2016; HALPERN et al, 2008; 2019; ROLIM et al, 2017; ZABALA, 2016). Por esse motivo, ações de comunicação, educação e conscientização foram incluídas como prioritárias, dentro do Plano de Ação em Ciência, Tecnologia e Inovação para os Oceanos, do Ministério de Ciências, Tecnologia, Inovação e Comunicações ((MCTIC), e o Programa de Formação de Recursos Humanos em Ciências do Mar (PPG-Mar), da Comissão Interministerial para os Recursos do Mar (CIRM). Nesse sentido, estratégias e abordagens inovadoras se fazem necessárias, visando disseminar o conhecimento sobre temas relacionados ao mar e sua proteção.

Num contexto em que que cada vez mais a população tem buscado os ambientes marinhos para desfrutar de momentos de lazer, mergulhar e observar a fauna (em especial aves, quelônios, cetáceos e peixes), passam a ser necessárias ações de educação não formal, baseadas em formas mais eficazes de sensibilizar o público, visando reduzir os impactos causados pela presença humana nesses ambientes e garantir a sua preservação, inclusive para manter os usos sociais, recreativos e econômicos dos ambientes marinhos e costeiros. Nesse sentido, estratégias usando tecnologias virtuais e dispositivos eletrônicos constituem ferramentas que podem ser usadas na educação ambiental formal e não formal (MOSER et al., 2020)

Uma abordagem inovadora que tem sido aplicada com objetivos educacionais e treinamentos profissionais envolve a utilização de vídeos em 360 graus (SNELSON; HSU, 2020), também conhecidos como Realidade Virtual (VR). Estes autores publicaram recentemente uma revisão sobre o tema, 
mostrando as vantagens da utilização de vídeos em 360 graus e algumas de suas aplicações. Estes vídeos são gravados em sistemas unidirecionais ou multicâmera, sendo exibidos simultaneamente, por meio de software, visando produzir um campo de visão esférico ou tridimensional, o que permite que o usuário possa olhar para qualquer direção durante a exibição do vídeo. Os vídeos podem ainda ser visualizados a partir de equipamentos simples, como smartfones, ou por dispositivos montados na cabeça (head mounted display HMD) (KAVANAGH et al., 2016).

A Realidade Virtual (VR) é uma tecnologia que utiliza a interface digital para simular um ambiente real ao usuário, convencendo-o de que ele se encontra em uma outra realidade, provocando alterações sensoriais que estimulam uma interação mais intensa e abrangente (PIMENTEL 1995), ou seja, cria ao individuo, um ambiente imersivo com o qual ele interage fisicamente e psicologicamente através da sensação proporcionada pela interface.

Os primeiros experimentos usando VR começaram nos anos 1960, ganhando força em 1990, com os jogos digitais (MENEGUETTE 2010). Hoje essa tecnologia vem sendo usada de forma crescente por pesquisadores em estudos de psicologia, engenharia, educação tecnológica, entre outros, permitindo a formatação de um espaço próprio, fechado entre o usuário e seu aparato, de forma a se sobrepor ao entorno e despertar a empatia do público para diversos temas. Por exemplo, Ardisara; Fung (2018) utilizaram vídeos 360 graus para simular atividades práticas de laboratório com alunos do curso de graduação em Química, visando demonstrar a operação de experimentos complexos com equipamentos de difícil operação. Além disso, a VR também podem ser utilizada como ferramenta de aprendizado sobre temas críticos, como aqueles relacionados com a sustentabilidade e a saúde ambiental, o que envolve a preservação do meio ambiente, a acidificação dos oceanos, o combate ao aquecimento global, a emergência e o tratamento de diversas patologias, e muitos outros temas. Recentemente, a National Geographic Society lançou uma série de vídeos de VR sobre diferentes temas relativos à natureza, visando a sua utilização na conservação ambiental, com grande repercussão entre o público (PALMINTIERI, 2019). Além disso, pesquisadores das universidades da Geórgia, de Connecticut e Stanford relataram que as experiências de realidade virtual podem aproximar as pessoas dos problemas e torná-las mais empáticas, pois alteram o comportamento do indivíduo, aumentando sua percepção e envolvimento com a natureza (AHN et al., 2016).

Nesse contexto, recentemente, Choi et al. (2018) apresentaram uma proposta de adaptação de smartfones para uso em realidade virtual, aplicando esta ferramenta para o ensino de biologia marinha, considerando aspectos da biodiversidade e impactos do lixo marinho. Em nosso melhor conhecimento, não há outros relatos na literatura sobre uso de vídeos 360 graus em atividades educacionais envolvendo o ambiente marinho-costeiro. De todo modo, de acordo com Ahn; Bailenson (2014), a realidade virtual realizada a partir de ambientes protegidos, ricos em biodiversidade, pode levar o indivíduo à sensação de estar presente no local, de modo a gerar uma conexão entre o eu e a natureza, o que 
por sua vez pode levar à sensibilização e um maior envolvimento com o ambiente natural, potencializando a percepção dos riscos ambientais, sendo então uma ferramenta eficaz na promoção do engajamento do público para o cuidado com a natureza. Além disso, é fato que as pessoas precisam vivenciar e conhecer o ambiente para querer protegê-lo, pois problemas ambientais que não são direta ou imediatamente observáveis ou conectados às suas experiências fazem com que as pessoas fiquem propensas a se sentir menos responsáveis, por causa da distância psicológica (UZZELL 2000). Como exemplo, Bandura (1997) diz que a experiência de realidade virtual catalisa uma mudança de atitude maior do que qualquer alteração desencadeada por um vídeo tratando do mesmo assunto, pois a exposição à informação por si só não facilita o aprendizado ou a mudança de comportamento, uma vez que o indivíduo deve engajar-se e processar o conteúdo da mensagem.

Segundo Tuan (1980), "dos cinco sentidos tradicionais, o homem depende mais conscientemente da visão do que aos demais sentidos para repensar o mundo", pois a visão é o sentido mais aguçado e o mais evoluído entre os animais, e portanto é aquele que pode ser melhor explorado em ferramentas de realidade virtual. Portanto, por meio da utilização desta técnica, vislumbra-se a possibilidade de conscientizar o ser humano sobre a importância da preservação dos oceanos.

Assim, este estudo partiu da hipótese que o uso de vídeos 360 graus como estratégia de ensino e aprendizado de temas sobre ecologia e conservação marinha pode constituir uma excelente ferramenta, pois é de fácil aplicação e tem, potencialmente, um grande poder de sensibilização e envolvimento do público envolvido. Temas que podem ser explorados por essas técnicas incluem as paisagens marinhas e sua beleza cénica, aspectos da vida marinha, e os impactos da ação humana sobre o ambiente marinho. Além disso, mesmo considerando que o oceano cobre mais de $70 \%$ da superfície do globo terrestre e interfere em muitos aspectos da vida diária dos habitantes do planeta, uma porcentagem significativa das pessoas, por variados motivos, possivelmente nunca terá a possibilidade de viver a experiência de estar no oceano.

\section{Objetivo}

Considerando o contexto apresentado acima, a presente investigação visou avaliar a eficácia do uso de óculos de realidade virtual como ferramenta para a conscientização ambiental na conservação da biodiversidade marinha, a partir do seu uso associado com uma pesquisa de opinião junto ao público.

\section{Materiais e métodos}

Para atingir o objetivo, foi montada uma tenda na Praia do Boqueirão (também conhecida como Canal 3), no município de Santos, litoral de São Paulo, Brasil. Durante um final de semana do mês de outubro de 2019, foi realizada uma atividade envolvendo questionários e a exibição dos vídeos para o público 
presente na praia, seguindo o protocolo proposto por Choi et al. (2018), conforme descrição a seguir.

Os dispositivos para exibição dos vídeos 360 graus consistiram em óculos de realidade virtual VR BOX, com espaço para encaixe de um aparelho de telefone celular do tipo smartfone para a apresentação de vídeos com a temática ambiental. Uma descrição detalhada desse tipo de dispositivo e suas características está apresentada em Choi et al. (2018). Os óculos VR BOX possuem alta qualidade, sendo feitos em resina e tendo foco e distância ajustáveis. Como esses óculos impedem a entrada de luz externa, proporcionam um maior isolamento do mundo exterior, facilitando a imersão do usuário na experiência relacionada com os vídeos. Essa experiência se torna mais realista devido ao ângulo das imagens (maior do que $110^{\circ}$ ), alta qualidade (resolução maior do que 4K), e aos quadros mais rápidos e estáveis ( $\mathrm{CHOl}$ et al. 2018). Além disso, juntamente com os óculos de RV, foram usados fones de ouvido, visando proporcionar ao público uma imersão virtual mais intensa e profunda na realidade contida nos filmes.

Foram usados quatro vídeos, disponíveis em livre acesso na plataforma YouTube, abordando temas relacionados com a biodiversidade marinha e as ameaças aos ecossistemas e organismos marinhos. Por se tratar de um estudo piloto, visando avaliar aspectos da aplicação do método, receptividade do público e potencial uso como ferramenta de educação, foram escolhidos filmes curtos, possibilitando realizar a atividade com um número maior de pessoas.

Os temas exibidos incluíram: 1) Golfinhos nadando no Mar Vermelho, em material produzido pela "The Dolphin Swim Club" para uso educativo em 360 graus, com duração de 2 minutos (https://youtu.be/BbT e8IWWdo); 2) Leões marinhos nas Ilhas Falklands (Malvinas), produzido pela "Wildlife Protection Solutions", com duração de 58 segundos (https://youtu.be/TuU4kA3SiW0). Nesse local, a população de leões marinhos foi dizimada por caçadores e não se recuperou, embora a caça tenha sido interrompida nos anos 1950. As razões possíveis incluem o aumento da temperatura da água do mar devido à mudança climática, ou a sobrepesca na região, reduzindo a disponibilidade de alimentos e a capacidade das fêmeas de alimentar seus filhotes; 3) Golfinho nadando com sacola plástica presa em seu focinho, em local desconhecido, produzido por "Paulphin Photography", com duração de cerca de 1 minuto (https://www.youtube.com/watch?v=YShGVggcHf4); e 4) Raia manta nadando no meio do lixo em vídeo elaborado pela "NatGeoWild" com duração de 57 segundos (https://www.youtube.com/watch?v=JLOVSfZ0yX4), no qual a raia nada em meio a uma grande quantidade de resíduos plásticos na costa de Nusa Penida, na Indonésia.

Antes de ser iniciada a exibição dos filmes, todas as pessoas assinaram um termo de consentimento e anuência, concordando em participar da atividade; no caso de menores de idade, o termo foi assinado pelos pais ou responsáveis. As pessoas também responderam a um primeiro questionário, tratando de suas expectativas em relação à imersão com os óculos, seu conhecimento sobre o ambiente marinho, sua importância e o que seria uma unidade de conservação (Tabela 1), o qual foi realizado oralmente, e cujas respostas foram gravadas para 
análise posterior. Foi assumido que, desta forma, o público poderia desenvolver os argumentos/raciocínio de uma forma mais compreensível do que pela escrita.

Tabela 1: Questionário aplicado ao público que assistiria aos vídeos 360 graus sobre a vida marinha, visando avaliar as expectativas e nível básico de conhecimento sobre o tema.

\begin{tabular}{|l|}
\hline Nome: \\
\hline Idade: \\
\hline Cidade: \\
\hline O que você imagina desta experiência? O que você está sentindo agora? \\
\hline Em sua opinião, qual a importância do ambiente marinho? \\
\hline E quais as ameaças que esses ambientes enfrentam? \\
\hline $\begin{array}{l}\text { Você sabe o que é uma área marinha protegida/unidade de conservação } \\
\text { marinha? }\end{array}$ \\
\hline
\end{tabular}

Já após a imersão, foram feitas as perguntas do segundo questionário abordando as opiniões sobre a atividade e os conteúdos exibidos, e as reações fisiológicas frente às imagens (Tabela 2). Ao final da atividade, foi realizada uma discussão (na forma de conversa informal) sobre a importância do oceano para a existência da vida no planeta, visando demonstrar a interrelação entre os ambientes marinhos e terrestres, a relevância da mudança de atitude em relação ào ambiente marinho, e a existência das Unidades de Conservação marinhas.

Tabela 2: Questionário aplicado ao público que assistiu aos vídeos 360 graus sobre a vida marinha, visando avaliar as reações, opiniões, e nível de conhecimento sobre o tema.

\begin{tabular}{l}
\hline $\begin{array}{l}\text { Como você se sentiu durante e após a imersão? } \\
\text { ambiente? Foi de acordo com a sua expectativa? }\end{array}$ \\
\hline $\begin{array}{l}\text { Em sua opinião, os óculos de realidade virtual são eficientes no quesito de envolver o indivíduo } \\
\text { no ambiente marinho? Você se sentiu envolvido? De que maneira e porquê? }\end{array}$ \\
\hline Após o vídeo, a sua percepção sobre a importância do ambiente marinho mudou? \\
\hline E agora, você sabe o que é uma área marinha protegida/unidade de conservação marinha? \\
\hline $\begin{array}{l}\text { Quais atitudes que você, de fato, pode mudar no seu dia a dia para contribuir a favor dos } \\
\text { oceanos e de toda natureza? }\end{array}$ \\
\hline
\end{tabular}

As respostas fornecidas pelo público foram avaliadas qualiquantitativamente, visando compreender as opiniões predominantes ou mais 
comuns. Também foram usados elementos presentes na análise de conteúdo, para auxiliar na descrição qualitativa das respostas e na reinterpretação das mensagens contidas nos discursos transcritos (MORAES, 1999, p.7). As respostas previamente gravadas de todos os participantes da pesquisa foram documentadas em uma planilha. Assim, conforme indicado por Olabuenaga; Ispizua (1989), buscou-se dividir os aspectos mais importantes ressaltados nos discursos, a partir da identificação de categorias, visando facilitar a análise. Estas categorias, quando presentes, deveriam trazer informações válidas, adequadas ao contexto e objetivo da atividade, e possuir íntima conexão com os conteúdos. As categorias deveriam ter ainda significados, passíveis de ser descritos e interpretados dentro de uma fundamentação teórica (LINCOLN; GUBA, 1985; MORAES, 1999).

\section{Resultados e Discussão}

No total, foram entrevistadas 80 pessoas, das quais 38 eram mulheres e 42 eram homens, compreendidos na faixa etária de 04 a 85 anos de idade, sendo: $0-9=03,10-25=27,26-45=23,46-55=17,56-65=05,66-75=04,76$ $85=01$. Em relação à origem: 29 participantes eram da cidade de São Paulo, 05 de Guarujá, 35 de Santos, 03 de São Vicente, 01 de Porto Alegre, 01 de Belo Horizonte, 01 da Venezuela, 01 da Espanha, 01 do Rio Grande do Sul e 01 de Itaúna/Bahia. As crianças que participaram da atividade com os óculos de realidade virtual não foram consideradas na pesquisa, por motivos éticos.

\section{Análise da expectativa em relação à experiência}

A análise da expectativa de cada entrevista teve 0 intuito de procurar entender o estado emocional de cada participante, já que esse fator poderia afetar o resultado da pesquisa. Também buscou-se conhecer o que cada participante esperava obter da atividade com os vídeos. Assim, com base nas respostas da questão 01 referente à Expectativa, foram definidas as seguintes unidades de contexto para a primeira parte da pergunta (Figura 1):

- Aprendizado de algo novo: o entrevistado esperava aprender algo novo e interessante;

- Boa causa: o entrevistado afirmou estar ali para ajudar no projeto, que foi considerado importante para o entrevistado;

- Divertida/animada: o entrevistado esperava se divertir com os óculos;

- Impactante: havia uma expectativa de ver algo impactante, como um desastre ambiental.

Já em relação à segunda parte desta pergunta, voltada para o estado de ânimo em relação à atividade, as unidades de contexto identificadas foram:

- Curioso: o indivíduo queria saber o que era o projeto e o que iria acontecer; - Ansioso: o indivíduo estava inquieto, na expectativa de experimentar os óculos; 
- Contente: o indivíduo estava animado em estar participando do projeto;

- Relaxado: o indivíduo se sentia tranquilo, à vontade naquele momento.

- Não sei: pessoas que não conseguiram definir como se sentiam antes da atividade.

Como é possível observar na Figura 1A, 66\% dos entrevistados não imaginavam como seria a experiência, enquanto $16 \%$ esperavam que o projeto Ihes forneceria um novo conhecimento. Os $10 \%$ que responderam "Por uma boa causa" mostraram interesse, se importando em auxiliar ao projeto. Já em relação ao estado emocional, no qual foi perguntado "O que você está sentindo agora", $39 \%$ reportaram estar curiosos, $28 \%$ ansiosos e $24 \%$ relaxados, à vontade e/ou tranquilos (Figura 1B).

\section{Expectativas do público}
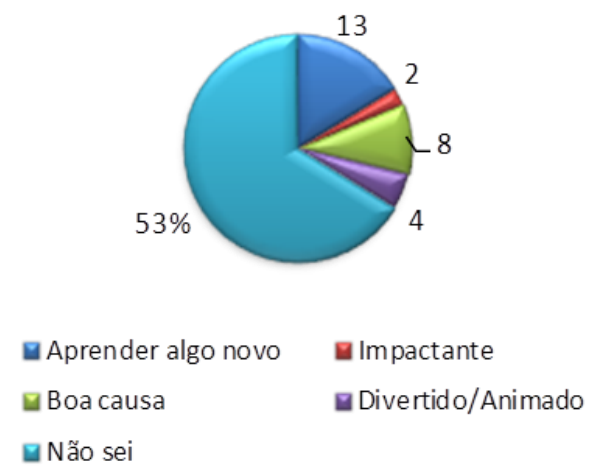

\section{Estado emocional}

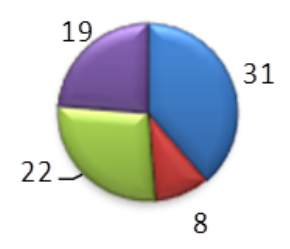

- Curioso

- Contente

$\square$ Ansioso

Q Relaxado, A vontade, Tranquilo

Figura 1A: Respostas dos entrevistados em relação às expectativas sobre a atividade usando vídeo 360 graus; e 1B: respectivos estados emocionais antes da atividade.

A segunda pergunta visou avaliar o nível de conhecimento dos entrevistados sobre a importância do ambiente marinho, informação fundamental para o entendimento do conhecimento basal sobre os conteúdos dos vídeos. As respostas fornecidas para essa questão 02 permitiram listar as seguintes unidades de contexto (Figura 2):

- Não sei: indivíduos que não souberam atribuir qualquer importância para o embiente marinho;

- Abrangente superficial: os entrevistados disseram que tudo é importante, e/ou respostas superficiais;

- Faz parte do ecossistema: os entrevistados parecem entender, ainda que de forma genérica e pouco aprofundada, que o equilíbrio do meio marinho é necessário para não comprometer outros ambientes; 
- Preservação para o futuro: estas unidades englobaram respostas informando que a causa dos problemas ambientais é o ser humano, e que o ambiente deve ser preservado para as gerações futuras, porém não citavam a importância;

- Questões da atualidade: Entrevistados comentaram sobre notícias atuais naquele momento, como o petróleo nas praias do Nordeste e o lixo.

\section{Conhecimento sobre importância do ambiente marinho}

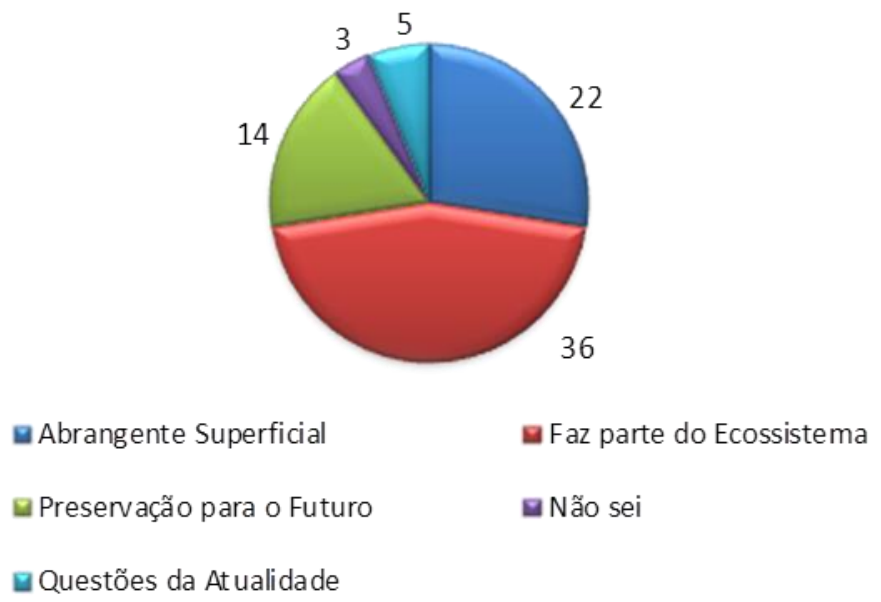

Figura 2: Respostas dos entrevistados sobre conhecimento prévio sobre a Importância do ambiente marinho. categorias:

Dentro dessas Unidades de contexto, foram criadas as seguintes

- Conhecimento limitado (utilitarista): Quando os indivíduos só conseguiram atribuir alguma importância para 0 ambiente marinho ressaltando benefícios econômicos diretos ao ser humano, como a passagem de embarcações, a entrada e saída de mercadorias e segurança do homem dentro da embarcação no mar. Em geral essa visão limitada esteve dentro de um viés anropocêntrico.

- Abrangente superficial: Neste caso, foi relatada uma importância genérica para a vida no planeta, sendo demonstrada alguma preocupação com o cuidado ao ambiente marinho, porém em alguns casos ainda dentro de uma visão antropocêntrica. Por exemplo "Se não preservar não é possível importar e exportar"; em outro caso, foi mencionada a importância para a cadeia alimentar, sem maiores explicações.

- Parcialmente conectada ao ecossistema: Nesse caso, os entrevistados conseguiram estabelecer algumas conexões com as funções dos ecossistemas marinhos ou os serviços ambientais, ainda que de forma inconsciente. Assim, as respostas integraram temas como: lazer, no qual o ambiente era visto como local 
de diversão, mas que tinha uma importância ecológica; preocupação com extinção dos animais marinhos; possibilidade biotecnológicas, através das quais estudos e descobertas poderiam levar a novas substâncias e medicamentos ou incentivo a pesquisa e obtenção de alimentos; geração de oxigênio atmosférico, através da fotossíntese pelas algas; e proteção aos animais aquáticos e corais.

- Preservação para o futuro: Alguns entrevistados demonstraram valorizar os ambientes marinhos, indicado que sua proteção deveria ser definida em leis e que todos precisam valorizar mais estes ambientes, tendo consciência da necessidade de proteção e da ameaça representada pelos impactos humanos sobre os ambientes marinhos;

Quatro porcento dos entrevistados que responderam "Não sel" para a questão que tratava da importância do ambiente marinho (Figura 2). O público deste grupo, quando solicitado a expressar suas ideias sobre o assunto, mostrou uma visão limitada, em geral de cunho antropocêntrico, onde o ser humano é visto como o centro do universo, não percebendo que o ambiente marinho é mais amplo e complexo do que somente os usos e interesses dados pelo ser humano. Outros 28\% responderam de forma superficial, relatando que o ambiente marinho era "tudo", e de certa forma, apresentando um conhecimento que misturava a visão antropocêntrica com uma visão sistêmica, sendo capazes de perceber, de forma incipiente, algumas interdependências entre os elementos que compõem o ambiente.

Devido à superficialidade das respostas, percebe-se uma dificuldade em estabelecer conexões entre os elementos do ambiente, e destes com o ser humano, que novamente aparece como o centro da questão, como na afirmação "Se não preservar não é possível importar e exportar", que claramente apresenta uma visão utilitarista para o meio marinho, uma vez que só atribui valor ao ambiente se este puder ser aproveitado economicamente pelo homem. Quarenta e cinco porcento dos indivíduos entrevistados responderam que o ambiente marinho faz parte do ecossistema e que seu equilíbrio compromete os demais ambientes. Todas as categorias dentro dessa unidade de contexto foram expressas de forma combinada, ou seja, uma a três categorias foram citadas pelos entrevistados quando perguntados sobre a importância do ambiente marinho. Por esta visão, a preocupação não se deu somente com o ser humano, mas já aparece o interesse nos ecossistemas e na biodiversidade, já que foram citadas a "Preocupação com a extinção" e "Proteção aos animais aquáticos e aos corais". Já $18 \%$ das pessoas mostraram um pensamento acerca do futuro, onde a importância do meio marinho está atrelada a mantê-lo preservado para as gerações futuras, o que se enquadra na direção de uma visão sistêmica, sendo ampla, porém ainda superficial, pois não foi de fato mencionada qual a importância do meio marinho. Ainda, $6 \%$ dos entrevistados focaram nas questões da atualidade, citando o desastre de vazamento de óleo no Nordeste, no qual as praias foram poluídas, mas que dentro disso, poucos citaram os animais oleados, como se o desastre maior fosse por conta da inviabilização das praias para os turistas, o que demonstra, ainda que em parte, uma visão antropocêntrica.

revista brasileira educação ambiental 
A terceira pergunta do questionário apresentado antes da atividade teve como objetivo analisar o conhecimento prévio que o público possuía sobre as ameaças atualmente existentes aos ambientes marinhos. Após um exame das respostas, foram definidas as seguintes unidades de contexto (Figura 3):

- Extinção da biota: quando os estrevistados manifestaram algum conhecimento ou preocupação com a ameaça de extinção de animais, grupos taxonômicos ou a biodiversidade de modo geral. Estas respostas indicaram algum grau de preocupação com a biodiversidade;

- Seres humanos, egoísmo e ganância: quando as respostas atribuíram, de forma explícita, uma total responsabilidade ou culpa ao ser humano, pelas ameaças aos ambientes marinhos. Nessa categoria foram classificadas as falas que identificaram como causas das ameaças a ação humana, de uma forma mais geral, devido ao egoísmo e a ganância. Também foram identificados elementos como a falta de conhecimento (da sociedade) sobre o assunto, o modelo de sociedade baseado no consumo excessivo, e o aumento da população global. Os entrevistados relataram ainda a desconexão do ser humano com o ambiente, e a perda do sentimento de empatia para com o ambiente marinho. Além disso, os discursos também abordaram aspectos sobre a educação da sociedade e a modernização;

- Poluição, lixo e outros impactos: quando as respostas se referiram à poluição causada pelo ser humano, especial aquela comum nas praias. Este item foi o mais frequentemente presente nas respostas, pois é o mais visto pela população em geral, em especial nas praias de Santos, onde a atividade foi conduzida. As respostas abordando esse assunto envolveram os casos em que impactos específicos sobre os ambientes marinhos foram identificados, tais como pesca ilegal; desmatamento; lançamento de esgoto no mar; descarte de resíduos, como plásticos, canudos e remédios; ou descartes ilegais de materiais e esgotos provenientes de navios, populações ribeirinhas e das próprias pessoas que frequentam a praia. Em relação ao lixo na praia, alguns respondentes identificaram esse item como a única ameaça;

- Descaso do governo: nestes casos, os participantes atribuíram ao governo, parcial ou integralmente, a responsabilidade pelos problemas ambientais percebidos.

- Aquecimento global: alguns entrevistados demonstraram um conhecimento relacionando a acidificação dos oceanos, causada pelo aquecimento global, e a morte dos corais;

- Petróleo no Nordeste: o caso da poluição por petróleo nas praias do nordeste brasileiro foi reconhecido, por se tratar de notícia que estava tendo grande repercussão na mídia na época em que a atividade foi conduzida;

- Não sei: indivíduos que não souberam responder ou elencar ameaças ou impactos sobre os oceanos. Nessa categoria encontram-se as pessoas com maior desconhecimento sobre o assunto, chegando a haver respostas indicando possiveis ameaças do ambiente marinho sobre o ser humano, como a 
identificação de tubarões como ameaça ao homem e ao ambiente marinho, ou o risco de estar atravessando mar em um barco e ocorrer um naufrágio.

Em relação a essa questão, houve entrevistados que citaram mais de uma unidade de contexto (Figura 3). Respostas como "atravessar o mar e afundar o barco" demonstram uma visão antropocêntrica, indicada por três indivíduos que responderam dessa mesma forma na importância do ambiente marinho. Um número pequeno dos entrevistados (4\%) respondeu que há ameaça de extinção dos animais marinhos, indicando um conhecimento geral; porém não conseguiram justificar essas respostas, demonstrando não entender a fundo qual seria a causa da extinção e que a informação que estas pessoas detêm é ainda fragmentada. Outros $24 \%$ responderam, sucintamente, que a ameaça ao ambiente marinho se deve ao homem, com sua ganância e egoísmo, falta de conhecimento, consumo excessivo, aumento da população e até a "falta de amor". Essa visão pode ser considerada sistêmica e mais ampla, conseguindo atribuir aos seres humanos a responsabilidade pelas ameaças ao ambiente marinho. Já $47 \%$ dos entrevistados responderam que poluição e lixo são a causa principal que ameaça os ambientes marinhos, sendo os resíduos sólidos os mais relatados, pois são estes os que mais afetam a estética dos ambientes naturais (BROTTO et al., 2012), sendo notados pelos turistas e por estudantes (KATON et al., 2014; SAVIETTO et al., 2014; PEDRINI; BOCHNIAK, 2013; PETROSILLO et al., 2007).

Foram citados também: pesca ilegal; problemas de saneamento básico; resíduos mais falados na mídia, como os canudos e sacolas plásticas; descarte ilegal proveniente de embarcações, população que vive nas encostas e aqueles que frequentam a praia, sugerindo que, por essa visão, o lixo seria proveniente da praia e/ou do mar, a partir dos navios e fontes externas. Um pequeno número (4\%) das pessoas apontou o descaso do governo, citando e discursando sobre o aquecimento global e o petróleo no Nordeste; além disso, $14 \%$ citaram explicitamente este último, possivelmente pelo fato de estar sendo amplamente divulgado na mídia na época em que a atividade foi conduzida. Este dado demonstra que quando informações sobre o meio ambiente são veículadas nas mídias com maior círculação, elas tendem a ser mais lembradas pela população. Entretanto, a presente pesquisa não permite saber até que ponto tais informações foram devidamente apreendidas e assimiladas pelos entrevistados. De acordo com (SILVA, 2017), as mídias podem ser fortes aliadas para a conscientização da população nas questões ambientais que precisam ganhar espaço na discussão de massa, e nesse sentido, o papel dos especialistas é importante para balizar o trabalho feito por jornalistas e comunicadores. 


\section{Ameaças aos ambientes marinhos}

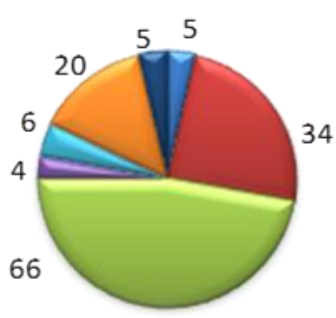

घExtinção dos Animais

aquecimento Global

mescaso do Governo
घ Seres Humanos, Egoísmo

घ Não sei
घPoluição, Lixo

- Petróleo no Nordeste. Óleos

Figura 3: Ameaças aos ambientes marinhos identificadas pelo público previamente à atividade de exibição dos vídeos 360 graus.

A quarta questão sobre conhecimento prévio visou identificar se (e como) o público possuía informações sobre Áreas Marinhas Protegidas (AMP; ou Unidades de Conservação Marinhas - UC) e para as respostas a ela foram definidas as seguintes unidades de contexto (Figura 4):

- Não sei: indivíduos que não souberam responder. Nessa categoria, foram incluídos diversos e variados relatos, como pessoas que ouviram falar sobre projetos ou organizações não governamentais (ONG); ou que seriam locais para manter e proteger animais em extinção. Alguns entrevistados afirmaram não haver proteção, seja para animais ou seres humanos;

- Designação de local onde há controle da presença humana: respostas que indicaram alguma informação abstrata ou dedutiva sobre as AMP, classificando estas áreas como local isolado do ser humano, e com proibição de certas atividades. Nessa categoria, a tendência foi de haver identificação das restrições, ainda que de forma descontextualizada dos objetivos de conservação. Foram relatados temas como exploração sustentável, relacionada com controle da pesca, da entrada de pessoas, da caça e da poluição; fiscalização para proteção do meio ambiente pela marinha e orgãos do governo, sendo o acesso controlado pelos mesmos; indicação de área restrita, onde não se pode pescar e encostar a embarcação; e atribuição de do termo reserva 100\% protegida, ou seja, local intocável onde ninguém pode adentrar, a não ser pesquisadores e voluntários; 


\section{Conhecimento prévio sobre o que é uma Unidade de Conservação Marinha}

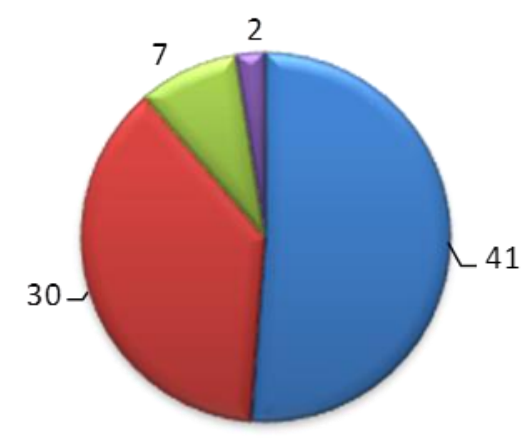

$\square$ Não sei $\square$ Local onde tem controle da presença humana $\square$ Citou Ucs $\square$ Confundiu com ONGs

Figura 4. Conhecimento prévio do público sobre Unidades de Conservação Marinhas (UC), antes da atividade de exibição e vídeo 360 graus.

- Citação explícita de UC: respostas em que foram citadas unidades de conservação, indicando algumas de suas características, como controle da entrada de pessoas e proibição de atividades poluidoras. Nesses casos, os respondentes indicaram as UC que escutaram falar e/ou visitaram, como os parques nacionais de Fernando de Noronha e Abrolhos, Parque Estadual Marinho da Laje de Santos, e Parque Estadual da Ilha Grande, entre outras;

- Confusão dos conceitos com ONG ou programas de conservação: casos em que os entrevistados citaram instituições, como IBAMA ou organizações não governamentais (ex. Greenpeace), ou projetos conservacionistas, como o TAMAR, confundindo-os com as áreas protegidas.

Cerca de $51 \%$ das pessoas não sabiam o que era uma UC, e quando estimuladas a expor sua opinião, diziam ter ouvido falar, através de projetos ou ONG. Três porcento pensavam que ONG e UC fossem a mesma coisa. Os termos "Unidade de Proteção" e "Área Marinha Protegida" são autoexplicativas e, por isso, muitos deduziam que nas UC havia "proteção" da biota, porém alguns indivíduos classificaram essas áreas como um lugar desprotegido no meio do oceano. Para $38 \%$ dos entrevistados, as UC possuíam controle da presença humana, porém de forma superficial; 21 pessoas disseram que uma AMP poderia ser explorada de forma sustentável, porém não entendiam a concepção do que pode ou não ser desenvolvido dentro delas. Um número reduzido de pessoas indicou haver grande restrição e intensa fiscalização, ou proibições parciais, ou limitação do acesso, ou proibições à pesca. Apenas $9 \%$ do público citaram exemplos de UC. Estas pessoas afirmaram ter tido a oportunidade de estar em uma UC e entendem que nelas o turísmo possui regras com o intuito de se preservar, o que demonstra a importância da existência do Uso Público como fator de educação e conscientização. 


\section{Análise da percepção após a atividade com óculos VR}

O segunto questionário visou compreender o resultado da exibição dos vídeos sobre os participantes sobre o estado psicológico, a partir de relatos sobre as suas reações. Após a leitura das respostas da Questão 01 desse questionário, foram definidas as seguintes unidades de contexto (Figura 5):

1) Calmo, Tranquilo: o indivíduo se sentiu relaxado durante e após a imersão.

2) Emocionado, Impressionado: o indivíduo ficou maravilhado durante e após a imersão. Em relação às sensações relatadas, destacam-se quem "sentiu como se estivesse lá", ou seja, os indivíduos se sentiram presentes no local do vídeo, e quem "sentiu vontade de mergulhar", indicando que os vídeos motivaram os indivíduos a querer conhecer o local.

3) Relembrou momentos: o indivíduo relembrou momentos de sua vida durante a imersão. Houve relatos de mergulhos passados, entre todos os indivíduos que já haviam mergulhado, tendo sido informado que a imersão trouxe ótimas lembranças de mergulhos passados. Também houve a lembrança de notícias passadas, pois após assistir ao segundo vídeo, indivíduos lembraram de notícias desastrosas com animais publicadas pela mídia.

4) Triste, Emocionado: esta unidade envolveu somente o segundo vídeo, no qual indivíduos relataram ter ficado emocionados, e tido vontade de ajudar, no sentido de retirar a sacola do focinho do golfinho.

5) Impactado, Angustiado: esta sensação tem a ver com os indivíduos que se sentiram impactados durante o segundo vídeo, e citaram a importância de descartar o lixo corretamente.

\section{Estado emocional dos participantes}
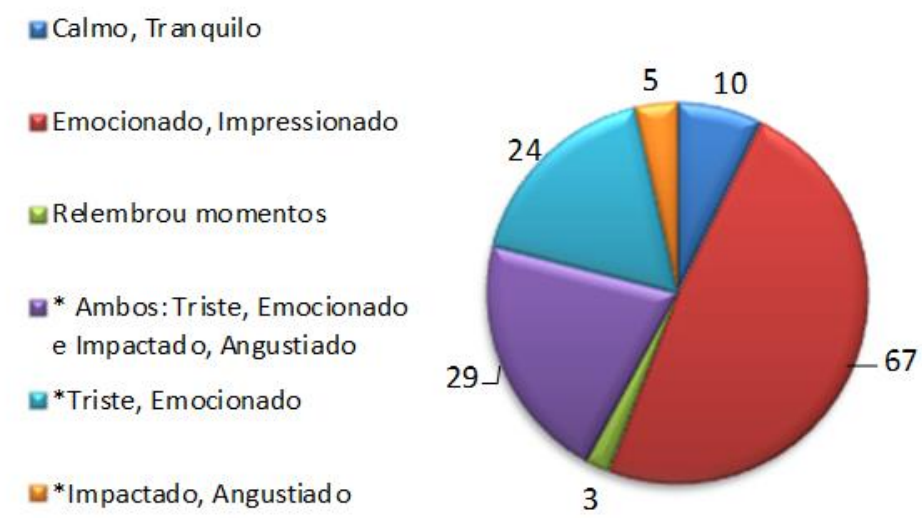

Figura 5: Respostas dos entrevistados em relação ao estado emocional após a atividade de imersão em realidade virtual

Os entrevistados utilizaram muitas palavras para expressar suas emoções ao responder à pergunta sobre como se sentiram durante e após a imersão, como 
"feliz", “maravilhado”, “encantado”, “emocionado”, “impressionado”, "tranquilo”, "calmo", "relaxado", “leve”, “impactado", "fantástico", "incrível”, "surreal”, "gostoso", "interativo", "real, "paz”, "feliz”, "legal”, "irado”, "baque”, “angustiado” e "triste". Esses sentimentos foram expressos em relação aos dois vídeos. Porém, 60 dos entrevistados não comentaram sobre o segundo vídeo, tendo relatado somente as emoções relativas ao primeiro filme. Isso se deve possivelmente por terem se sentido maravilhados ao ver os golfinhos nadando. Outros 10 entrevistados comentaram somente do segundo vídeo, sem citar o primeiro, possivelmente por terem se sentido de alguma forma impactados ao assistir a sacola plástica presa no focinho do golfinho. Outros 10 indivíduos comentaram sobre os dois vídeos, expressando os sentimentos para ambos, enquanto $4 \%$ dos Indivíduos citaram que o segundo vídeo os fez lembrar da importância de descartar corretamente o lixo, pois perceberam o que pode acontecer caso esse material acabe sendo lançado no mar. Um deles perguntou "se o lixo chega ao fundo do mar", o que sugere ainda haver desconhecimento do tema pela população, pois como as pessoas só vêm o lixo na superfície do mar ou na praia, e nem sempre conseguem compreender que os resíduos afundam. Dezessete por cento dos entrevistados ficaram tristes com o segundo vídeo, citando: "senti vontade de ajudar o golfinho", "Senti vontade de retirar a sacola dele" e, apesar da baixa qualidade do vídeo, muitos indivíduos disseram ter sentido empatia em relação ao animal, citando: "Muito triste, não joguem lixo, por favor", "Triste ver os golfinhos sofrendo e não poder ajudar", "É desesperador", "Senti pena do golfinho, é um desprezo do ser humano".

Dois entrevistados, que já haviam realizado mergulho, disseram que o primeiro vídeo dos golfinhos, os fez relembrar de ótimos momentos vividos no passado: "Parece que eu estava mergulhando de novo, é realmente muito real"; já $49 \%$ dos entrevistados se sentiram emocionados e impressionados, e relataram ter sentido a presença dos golfinhos: "Eu estava no Paraíso", "É muito real", "Parecia que eu estava sentado lá observando eles", "Me senti feliz, é muito gostosa a sensação". Em seguida estes indivíduos disseram sentir vontade de estar de fato presentes no ambiente real e/ou conhecer o mar da forma que estava sendo exibida no vídeo, ou seja, vivenciar aquele momento no ambiental real. Entre os entrevistados, havia pessoas que disseram ter pavor de água e que não colocariam nunca uma máscara de mergulho, mas que a realidade virtual foi uma possibilidade de levá-las até o fundo do mar, e que mesmo com seus medos, o sentimento dessas pessoas foi de "Bem estar, paz e tranquilidade". Essa última observação é muito importante, pois saber que a realidade virtual proporciona bem estar para pessoas com fobia de mergulhar e/ou vestir as máscaras de mergulho no rosto, nos mostra que é possível não só sensibilizar o indivíduo, como também auxiliar em relação a seus medos.

A segunda pergunta tinha como objetivo compreender se a opinião dos participantes sobre os vídeos e a experiência sensorial do uso dos óculos de RV, e se suas expectativas haviam sido atingidas. Em relação às respostas para essa questão, foram definidas as seguintes unidades de contexto (Figura 6):

1) De acordo com a expectativa: o vídeo atendeu às expectativas dos indivíduos. 
2) Mais ou menos de acordo com a expectativa: o vídeo não atendeu a todas as expectativas dos indivíduos.

3) Muito mais do que a expectativa: o vídeo ultrapassou as expectativas dos indivíduos, sendo muito melhor.

4) Não sei: o indivíduo não soube expressar como se sentiu ou emitir sua opinião em relação aos vídeos.

Os relatos feitos pelos participantes expressaram reações positivas, como "bem legal" (SIC), ou a vontade de tocar e interagir fisicamente com os golfinhos, ou sensações de estarem no mar nadando junto com os animais.

\section{Opinião sobre o uso dos óculos de realidade virtual}

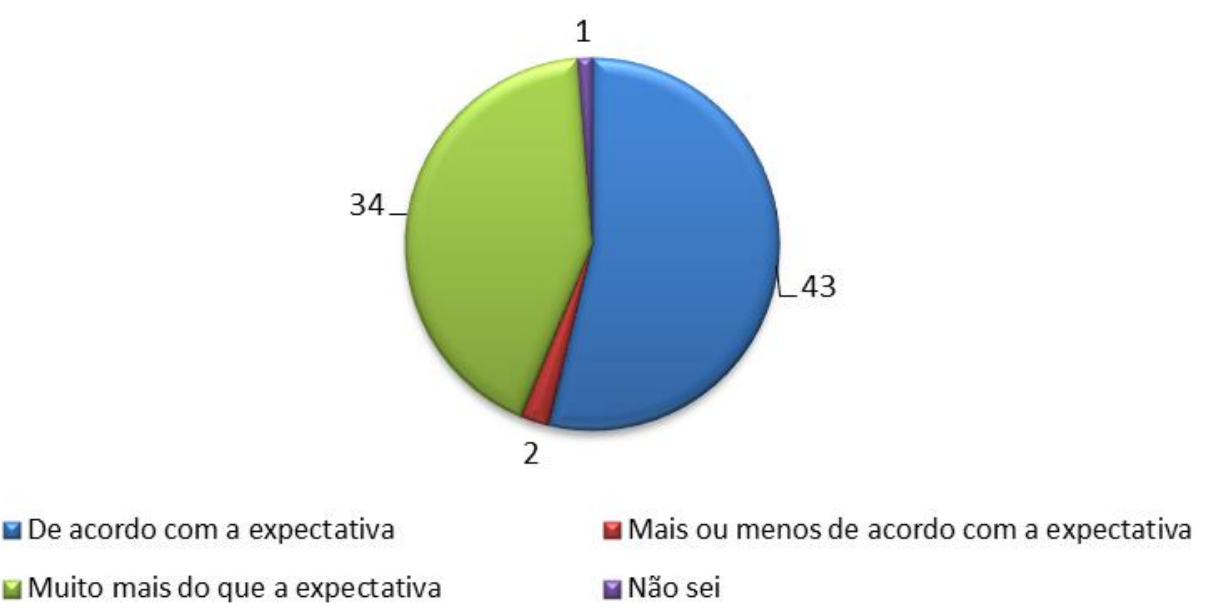

Figura 6: Respostas dos entrevistados sobre sua opinião em relação ao uso dos óculos de realidade virtual.

A maioria dos entrevistados (54\%) relatou que a experiência de estar próximo desses animais marinhos atendeu às expectativas, sendo citado por um deles "É uma vivência sensacional". Somente $3 \%$ dos entrevistados relataram que o vídeo não atendeu muito às suas expectativas, pois de acordo com eles "Esperava mais interação dos golfinhos" e "Esperava ver mais animais". Apenas um entrevistado não sabia como se sentia. Por outro lado, $43 \%$ dos entrevistados disseram que o vídeo ultrapassou suas expectativas de forma positiva "Foi muito além, espero um dia ter oportunidade de estar com eles", "Superou minha expectativa", "Eu não imaginava como seria e foi muito melhor", "Me senti privilegiado de assistir o vídeo", "Parece que faço parte do ambiente deles". Houve outros comentários como: "Gostei muito, pois é difícil ver golfinhos, ainda mais dessa forma na realidade", "Senti uma paz interior, próximo à natureza", "Eles são a melhor companhia", "não sei nadar e me senti muito calmo", "Parecia 
que eu estava do lado deles mesmo", "Incrível", "emocionante". Esses relatos mostram o quanto a ferramenta VR pode ser impactante, no sentido de criar uma conexão entre o ser humano e a natureza. Considerando a ideia já consolidada que para o ser humano querer preservar é necessário antes conhecer e possuir conexões com os objetos, a ferramenta de VR aproxima o indivíduo da realidade atual em que os oceanos se encontram. Além disso, como demonstrado, a VR pode ser especialmente importante para determinadas pessoas que sentem algum tipo de medo ligado ao mar, pois ao aceitarem colocar os óculos de VR e imergirem dentro do mar vistual, abrem espaço para enfrentar seus medos de uma forma simples e divertida, ou, no mínimo, conhecer o ambiente marinho sem se sentirem ameaçadas.

A terceira questão visou avaliar a opinião dos participantes sobre a eficiência do uso dos óculos de realidade virtual para envolver os indivíduos. Após a leitura das respostas fornecidas a essa questão, foram definidas as seguintes unidades de contexto para a pergunta:

1) Eficientes: os indivíduos acharam os óculos de VR eficientes, e se sentiram completamente imersos na realidade virtual, estando totalmente envolvidos.

2) Mais ou menos eficientes: os indivíduos não acharam os óculos de realidade virtual tão eficientes, pois não se sentiram totalmente imersos.

A grande maioria (99\%) dos indivíduos relatou que os óculos de realidade virtual são eficientes no quesito de envolver uma pessoa no ambiente marinho. Alguns participantes disseram sentir que estavam nadando no oceano, totalmente imersos na realidade virtual, onde um deles acrescentou "Pois você olha pra cima e vê a superfície, ai olha pra baixo e vê a areia, incrível", "Me senti em paz", "A experiência é muito próxima da realidade". Denota-se, com esses comentários, que os óculos de realidade virtual têm um poder de envolver o indivíduo no ambiente mostrado pelo vídeo. Entre os entrevistados, alguns citaram: "É incrível, porque a maioria das pessoas não sabem o que é o ambiente marinho e, estando aqui, podemos ver como realmente é", "É uma oportunidade de estar em um lugar que nunca imaginei estar", "Se todos tivessem a oportunidade de ver isso, teriam mais cuidado com seu lixo", "É rápido e objetivo, muito bom". De acordo com os entrevistados, os óculos de realidade virtual oferecem uma experiência diferente, aliando a capacidade de conscientizar e sensibilizar os indivíduos para os prejuízos ao ambiente devido a ações antrópicas. A única pessoa que assinalou a ferramenta como mais ou menos eficiente justificou-se dizendo que esperava mais dos óculos, "Queria sentir mais". Nesse sentido, depreende-se que foi criada uma expectativa maior do que os óculos comuns de realidade virtual utilizados no trabalho puderam oferecer.

Por sua vez, a quarta questão visou avaliar a opinião dos participantes sobre a importância do ambiente marinho, após a atividade de imersão. Para as respostas, foram atribuídas as seguintes unidades de contexto (Figura 7):

1. Mudança de opinião: a opinião do indivíduo sobre a importância do ambiente marinho mudou depois de passar pela imersão, em geral atribuindo maior importância; 
2. Opinião se manteve igual: a opinião do indivíduo sobre a importância do ambiente marinho não mudou depois de passar pela imersão;

3. Reforçou uma opinião pré-existente: nestes casos, a opinião do indivíduo sobre a importância do ambiente marinho foi aumentada após a imersão.

4. Não sei: o indivíduo não soube responder.

\section{Opinião sobre a importância do ambiente marinho após a imersão}

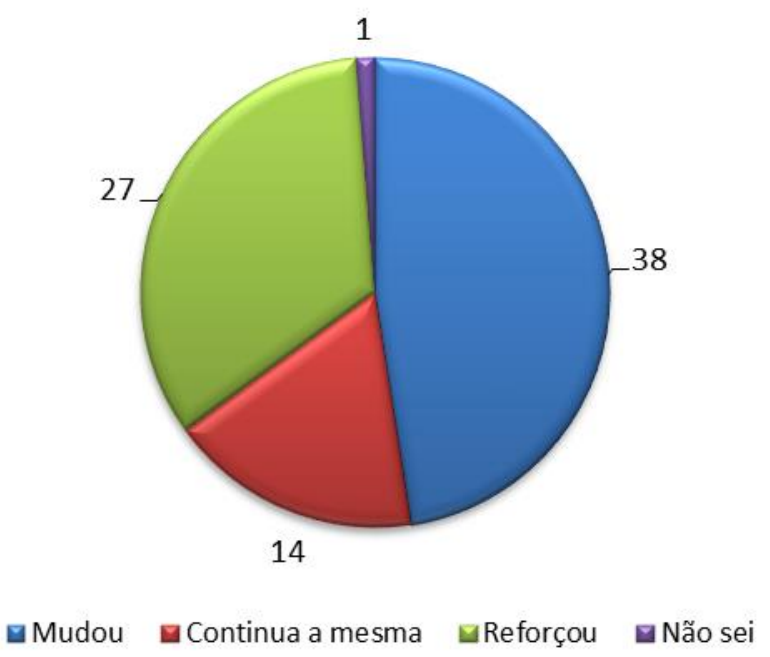

Figura 7: Respostas dos entrevistados sobre a opinião sobre a importância do ambiente marinhos após a imersão em realidade virtual

Quase a metade (48\%) dos entrevistados afirmou que sua opinião sobre a importância do ambiente marinho mudou após terem passado pela experiência de RV com os óculos 360, citando: "Por esses óculos, tem se uma consciência melhor do que acontece na vida marinha", "Ele tem o poder de conscientizar as pessoas", "Mostra quanta responsabilidade temos que ter", "Mudou, porque podemos ver que os lixos matam os animais", "Puder ver com mais clareza o que eles passam". Esses relatos mostram que após assistir um vídeo 360 de golfinhos nadando e em seguida outro vídeo impactante de um golfinho com uma sacola presa em seu focinho fizeram com que a visão dessas pessoas mudasse. Nesse sentido, em atividades de educação ambiental, é necessário envolver as pessoas com os temas e contextos, visando facilitar os passos seguintes, de reflexão e aprendizado, e os óculos $360^{\circ}$ podem contribuir para essa finalidade. Apenas $18 \%$ dos entrevistados responderam que sua percepção continuou a mesma após a imersão, com a justificativa de que não mudou por já se considerarem conscientes, porém nesse caso, estes indivíduos entenderam a pergunta feita como se eles fossem ou não conscientes sobre o ambiente marinho e, eles já sabendo sua importância, não teriam porque ter mudado sua opinião. Uma parcela significativa (34\%) dos entrevistados disse que após a 
exibição dos vídeos por VR, sua percepção foi "Reafirmada", "Aumentada", "Reforçada", "Fortalecida", e também duas pessoas citaram "Para aqueles que não tem conhecimento, que poluem, é uma boa alternativa, porque é um choque de realidade". Assim, 'possível depreender que a experiência com VR pode funcionar também para reforçar aspectos de reflexão e aprendizado de um indivíduo.

Em relação às respostas para a questão 05 , envolvendo a opinião do que é uma UC marinha (ou AMP), após a imersão, foram definidas somente duas unidades de contexto:

1. Local de proteção aos animais: o indivíduo diz que a UC é uma área com o intuito de proteger os animais, onde é proibido prejudicar o ambiente e não há degradação de nenhum tipo.

2. Não sei: o indivíduo não soube dizer o que era uma UC.

A grande maioria, ou seja, $98 \%$ dos entrevistados, disse que uma unidade de conservação é uma área que tem por intuito proteger os animais marinhos e terrestres, não permitindo nenhum tipo de degradação ao ambiente, por exemplo: "Área sem poluição, restrita aos humanos", "Local onde os biólogos protegem", "Manter o ambiente natural para os animais marinhos", "Local sem poluição", "Área de proteção e reprodução dos animais marinhos, onde não pode pescar, o ser humano não pode entrar e navegar". De modo geral, foi entendido que a UC é uma área onde o ser humano não pode entrar, ou se puder, seria "Interagindo com os animais de forma a se preservar", e onde não deveria haver nenhum tipo de contato com o lixo, a não ser provindo pelo meio do próprio mar. Muitos relacionaram o aprendizado com o vídeo assistido: "Área como no vídeo", "Área como essa que os animais vivem bem assim", "Igual ao vídeo", "Vendo a situação do golfinho, sabe se que deve proteger e lutar pela vida dos animais marinhos", "Área sem poluição, onde os animais estão em paz como no vídeo", "Lugar onde os golfinhos estavam, porque estavam seguros". Percebe se que o vídeo, mesmo sem fornecer mais informações (i.e. somente golfinhos), já teve a capacidade de mostrar ao público, de forma intuitiva, qual o objetivo de uma UC. Porém, $3 \%$ dos entrevistados continuavam sem saber o que era uma UC: "Não consegui extrair nada dos vídeos".

A sexta questão visava obter informações sobre como o indivíduo poderia contribuir de forma positiva para os oceanos e a natureza, a partir de mudanças em suas atitudes cotidianas (Figura 8). Após a leitura das respostas, foram definidas quatro unidades de contexto:

1. Divulgar: o indivíduo diz que pode contribuir com o meio ambiente através da disseminação da informação.

2. Reciclar e reutilizar: o indivíduo diz que pode contribuir com o meio ambiente através da reciclagem e reutilização de materiais.

3. Destinação do lixo: o indivíduo diz que pode contribuir com o meio ambiente jogando o lixo em lugares corretos.

4. Menor consumo de plástico: o indivíduo diz que pode contribuir com o meio ambiente consumindo menos plástico e utensílios de descarte rápido. 


\section{Contribuição para uma mudança positiva}

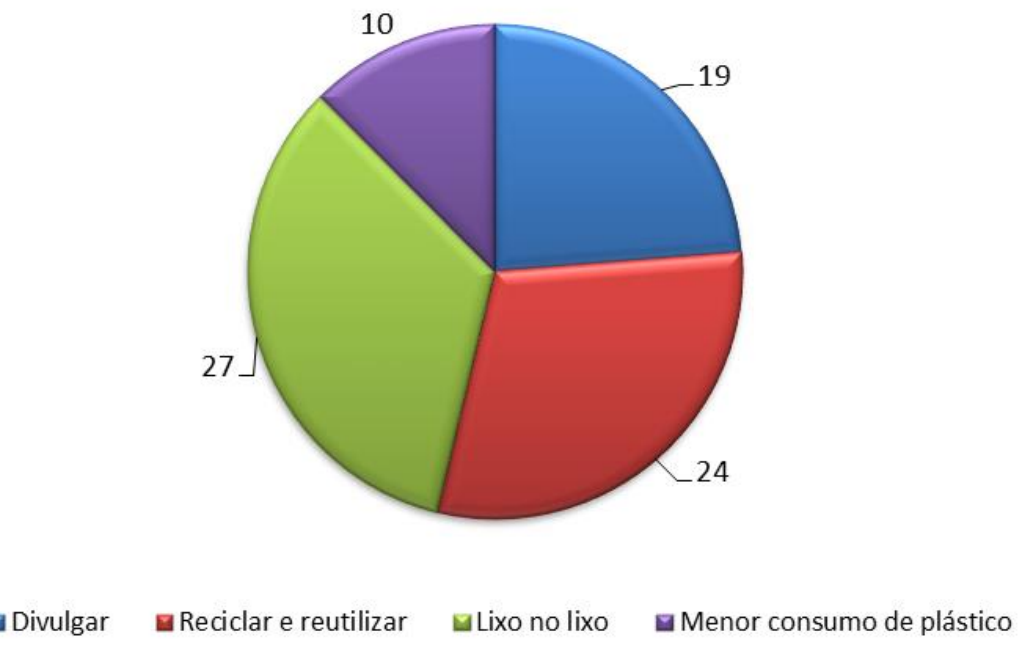

Figura 8: Respostas dos entrevistados em relação à contribuição que poderiam fazer em favor do meio ambiente.

De forma geral, a maioria dos indivíduos citou que poderia contribuir a favor do meio ambiente, realizando o descarte dos resíduos de forma correta e/ou reciclando, ou divulgando para pessoas de seu círculo de convívio e a outros de fora. Trinta e quatro por cento dos entrevistados disseram que iriam melhorar suas atitudes, jogando o lixo no lixo, porém denota-se que para estes participantes, jogar o lixo dentro de uma lixeira já seria suficiente para resolver o problema dos resíduos sólidos, não havendo o conhecimento e tampouco uma reflexão sobre a complexidade do problema, como por exemplo, a necessidade de tratamento e destinação correta, ou a conexão desse problema com a saúde pública. Tal fato ressalta a importância de se utilizar a VR em conjunto com outras ferramentas educacionais, criando sentido para as informações e conexões com outros temas. Outros $30 \%$ aliaram o descarte correto à ideia de que é necessário reciclar, enquanto $24 \%$ relataram a necessidade de informar as pessoas que poluem, pois acreditam que disseminar a informação é a melhor forma de conscientizar um indivíduo. Por fim, somente 13\% disseram poder auxiliar com o menor consumo de plástico e embalagens descartáveis.

Embora o presente estudo tenha um caráter experimental, foi possível verificar a boa aceitação da VR entre o público participante, assim como estimar, ainda de forma preliminar, como esta abordagem pode ser útil em ações voltadas à educação e conscientização ambiental. Alta aceitação também foi reportada por Taylor; Disinger (1997), em um estudo prospectivo relacionado à Educação Ambiental. A realidade virtual tem sido utilizada em diversas áreas do conhecimento, como arquitetura, engenharia, medicina, robótica, ciências espaciais, treinamento militar, entre outras (FREINA; OTT, 2015), com a finalidade de educação e treinamento (BASU; JOHNSEN, 2014; ROUSSOU, 
2004; GARRIS et al., 2002). Ainda no início da década de 1990 Helsel (1992) destacou as possibilidades do uso desta ferramenta com fins educacionais, ainda que muitos aspectos conceituais, tecnológicos, psicológicos e éticos precisassem ser melhor compreendidos.

Em educação ambiental, o uso de realidade virtual tem sido recomendado por vários autores (TAYLOR; GISINGER, 1997; MIKROPOULOS et al., 1997, HOME; THOMPSON, 2008), embora relatos sobre usos e experiências sejam ainda relativamente escassos. Em temas relacionados com a conservação marinha, o uso de VR ainda é incipiente, porém já existem publicações interessantes sobre o tema. Lu; Liu (2015) descreveram o uso de realidade aumentada na educação marinha de estudantes do ensino fundamental em Taiwan, obtendo bons resultados e notando melhor desempenho após o uso dessas tecnologias. Mais recentemente, Fauville et al. (2020) realizaram uma atividade sobre acidificação marinha, destacando que a VR oferece algumas boas possibilidades, como empoderamento, a aquisição de novas perspectivas e visualização, constituindo uma boa ferramenta para educadores marinhos.

O presente estudo confirma as proposições feitas pelos autores acima citados, pois permitiu registrar que, após a imersão, houve uma resposta psicológica de conexão com o ambiente marinho, já que muitos participantes ficaram emocionados e reflexivos, após assistirem aos vídeos. Também houve respostas psicológicas nos entrevistados, conforme relatado, Nos casos de entrevistados que já dispunham de algum conhecimento prévio, houve um fortalecimento de ideias pré-existentes a respeito da importância dos ambientes marinhos e costeiros. Os participantes puderam relatar terem tido uma opotunidade de reflexão e conscientização sobre a sua responsabilidade em relação à natureza.

Da mesma forma, após a imersão, os participantes demonstraram intuitivamente serem capazes de compreender o que seria uma área marinha protegida, relacionando o conceito com as imagens. Devemos destacar que pelo caráter experimental da atividade, os vídeos exibidos eram simples, não sendo esperado que transmitissem muitas informações de forma mais organizada; além disso, não eram autoexplicativos e nem haviam sido produzidos especificamente com a finalidade de uso em educação ambiental. Dessa forma, ainda que não permitissem um maior aprofundamento nos conteúdos e conceitos, permitiam que os participantes deduzissem que uma UC marinha deveria ser um local sem poluição, e com restrições à presença humana. Além disso, possibilitaram uma reflexão sobre a existência de uma área marinha que precisa ser protegida, devido a múltiplas razões. Esses aspectos, somados com as conversas após a exibição dos filmes em VR, permitiu aos 80 entrevistados compreender, de uma forma mais adequada, o que é uma unidade de conservação e qual sua importância.

A utilização dos óculos de VR como ferramenta para envolver o público na conservação da biodiversidade marinha, também se mostrou eficiente, ultrapassando as expectativas de muitos entrevistados, os quais relataram 
frequentemente sensações de bem estar. Destaque deve ser dado aos participantes com fobia de água, que se sentiram confortáveis durante a imersão. Freina; Ott (2015) discutiram a vantagem do uso de tecnologias de VR em algumas situações, as quais incluíam a dificuldade de acesso físico e aspectos relacionados a situações de perigo. Nesse sentido, a tecnologia de imersão em VR oferece às pessoas a oportunidade de experimentar novas sensações, como mergulhar junto de animais e estar em lugares que nunca imaginaram. Em virtude disso, pode se afirmar que a realidade virtual pode constituir uma boa ferramenta para a educação ambiental e conservação marinha, sendo capaz de informar, sensibilizar e conscientizar as pessoas acerca da conservação do ambiente marinho. Sendo assim, por permitir que as pessoas experimentem, virtualmente, a realidade e os problemas ambientais, as ferramentas de VR podem levar essas pessoas a posturas mais críticas (RAJECKI, 1982), sendo portanto mais efetivas do que as formas passivas de transmissão de conhecimento, quando as pessoas apenas recebem descrições do problema (RIBEIRO et al., 2020).

O uso combinado de VR, conversas e questionários também permitiu extrair algumas informações básicas sobre o conhecimento dos participantes a respeito da questão ambiental. As respostas com maiores riquezas de informação correspondem a um maior conhecimento ecológico; nesse sentido, as respostas mais abrangentes dependeriam da história de vida dos entrevistados, sua experiência e capacidade de discernimento. Assim, maiores riquezas de informação possivelmente indicariam uma percepção ambiental abrangente, pela qual as pessoas estariam mais conectadas com o ambiente $\mathrm{e}$ a Teia da Vida (PEDRINI; DE-PAULA, 2011). Por outro lado, este uso combinado de ferramentas permitiu perceber algumas incoerências no discurso dos participantes. Os entrevistados citaram frequentemente impactos ambientais negativos que vinham sendo veículados na mídia ou são comumente discutidos, como esgoto (98\%), lixo (86\%) e óleo $(80 \%)$, porém não eram capazes de perceber a sua própria responsabilidade, o que corrobora resultados de estudos prévios realizados com turistas em ambientes marinhos (BERCHEZ et al., 2005; MELO et al., 2005; PEDRINI et al. 2007, 2011; SILVA, 2017; GHILARDI-LOPES et al., 2012). Ao mesmo tempo, as informações obtidas indicaram claramente que boa parte dos participantes não dispunha de um repertório de informações organizadas e coerentes sobre 0 ambiente marinho e sua proteção, frequentemente situando-se na superficialidade do conhecimento, e não entendendo muito bem as relações entre os fenômenos. Assim, frequentemente repetiram chavões ou fizeram afirmações desencontradas, demonstrando não compreender bem os aspectos que as envolviam. Contudo, o uso de ferramentas que estimulem a reflexão pode ter um potencial para mudar essa situação atual, como as abordagens de imersão em realidade virtual, por exemplo.

\section{Conclusão}

O presente estudo conclui que o uso de imersão em realidade virtual constitui uma ferramenta viável, de custo relativamente baixo, e efetiva para fins 
de educação ambiental sobre conservação marinha. Sua aplicação possui um alto potencial para conscientizar, emocionar e sensibilizar as pessoas, permitindo não só a transmissão de informações de uma forma eficaz, lúdica e agradável, mas também despertando a reflexão entre o público. Além disso, seu uso combinado com outras abordagens, como questionários e discussões, pode tornar a atividade mais efetiva, no sentido de estimular a reflexão, a conexão das diferentes informações e o despertar de uma visão crítica. Esse uso combinado também permite extrair informações sobre lacunas e incoerências no conhecimento prévio dos participantes, permitindo que discussões sejam direcionadas no sentido de cobrir tais aspectos. No presente estudo foi notória a falta de conhecimento prévio entre o público, ressaltando a necessidade de uso de ferramentas mais efetivas na educação ambiental.

Por fim, e considerando que o presente estudo foi um piloto, que utilizou as ferramentas de uma forma incipiente, para testar a abordagem, pode-se inferir que os vídeos podem ser aprimorados para uso em educação ambiental, cobrindo temas específicos de forma mais abrangente. Para este fim, podem ser desenvolvidos filmes específicos, abrangendo variados temas referentes ao ambiente marinho, ou conservação, ou os diversos impactos antrópicos, sendo produzidos com imagens de maior qualidade e definição, e levando em consideração aspectos psicológicos que facilitem o relaxamento e o envolvimento dos participantes. Também é possível pensar no uso alternado com outros vídeos autoexplicativos ou que contenham descrições sucintas, de modo que as possibilidades de uso de RV para educação marinha são bastante promissoras e variadas.

\section{Agradecimentos}

Os autores agradecem aos participantes do estudo e à UNESP Campus do Litoral Paulista pelo apoio ao projeto. AJRGS agradece imensamente à Lays Fernanda, Marcella Duarte Nathaly Araújo, Tereza Ratzka, Rosemeire Ratzka, Lino Barbosa e todos os remadores da Olukai Hoe pelo suporte, e à Taleessa Nunes e Maneco Francisco pelo apoio em campo. DMSA agradece ao Conselho Nacional de Desenvolvimento Científico e Tecnológico (CNPq) pela bolsa produtividade $\mathrm{PQ}$.

\section{Referências bibliográficas}

ABESSA, D., FAMÁ, A. BURUAEM, L. The systematic dismantling of Brazilian environmental laws risks losses on all fronts. Nature Ecology and Evolution, v.3, p. 510-511, 2019 https://doi.org/10.1038/s41559-019-0855-9

AHN, G.J.S; BAILENSON, N.J; PARK, D. Short- and long-term effects of embodied experiences in immersive virtual environments on environmental locus of control and behavior. Computer in Human Behavior, v. 39. p. 235-245, 2014. 
AHN, J.S; BOSTICK. J; OGLE. E; NOWAK. L.K; MCGILLICUDDY. T.K; BAILENSON. N.J. Vivenciando a Natureza: Incorporando Animais em Ambientes Virtuais Imersivos Aumenta a Inclusão da Natureza no Eu e Envolvimento com a Natureza. Oxford Academic, v. 21, ed.. 6, p. 399-419. 2016. Disponível em: https://academic.oup.com/jcmc/article/21/6/399/4161788

ARDISARA, A., FUNG, F.M. Integrating $360^{\circ}$ videos in an undergraduate chemistry laboratory course. Journal of Chemical Education, v. 95, p. 18811884, 2018. https://doi.org/10.1021/acs.jchemed.8b00143

BANDURA. A. Self-efficacy: The exercise of control. New York: Freeman. 1997.

BASU, A.; JOHNSEN, K. Ubiquitous virtual reality 'To-Go'. In: Virtual Reality (VR). IEEE, p. 161-162. 2014.

BERCHEZ, F.A.S.; CARVALHAL, F.; ROBIM, M.J. Underwater interpretative trail: guidance to improve education and decrease ecological damage. International Journal of Enviroment and Sustainable Development, v. 4, n. 2, p. 128-139, 2005.

BROTTO, D.S; PEDRINI, A.G; BANDEIRA, R.R.C; ZEE, D.M.W. Percepção ambiental do mergulhador recreativo no Município do Rio de Janeiro e adjacências: subsídios para a sustentabilidade do ecoturismo marinho. Revista Brasileira de Ecoturismo, São Paulo. v. 5, n. 2, p. 297-314, $2012 .$.

CHOI, K., YOON, Y.-J., SONG, H.-Y., CHOI, S.-M. Interactive and immersive learning using $360^{\circ}$ virtual reality contents on mobile platforms. Mobile Information Systems. 2018. Volume 2018, Article ID 2306031. https://doi.org/10.1155/2018/2306031

FAUVILLE, G., QUEIROZ, A.C.M., HAMBRICK, L., BROWN, B.A., BAILENSON, J.M. Participatory research on using virtual reality to teach ocean acidification: a study in the marine education community. Journal of Environmental Education Research, 2020, https://doi.org/10.1080/13504622.2020.1803797

FERREIRA, A.C., LACERDA, L.D. Degradation and conservation of Brazilian mangroves, status and perspectives. Ocean and Coastal Management, v. 125, p. 38-46, 2016.

FREINA, L., OTT, M.A Literature review on immersive virtual reality in education: state of the art and perspectives. In: The International Scientific Conference eLearning and Software for Education; Bucharest, v.1, pp.133-141. Bucharest: "Carol I" National Defence University. 2015. Disponível em https://progesis.itd.cnr.it/download/eLSE\%202015\%20Freina\%20Ott\%20Paper. pdf. Acesso em 20 set 2020.

GARRIS, R., AHLERS, R., DRISKELL, J. E. Games, motivation, and learning: A research and practice model. Simulation \& Gaming, v. 33, n. 4, p. 441-467, 2002. 
GHILARDI-LOPES, N.P; HADEL, V.F; BERCHEZ, F. Guia para Educação Ambiental em Costões Rochosos. Porto Alegre: Artmed, 2012. 200 p.

HALPERN, B.S., WALBRIDGE, S., SELKOE, K.A., KAPPEL, C.V., MICHELI, F., D'AGROSA, C., BRUNO, J.F., CASEY, K.S., EBERT, C., FOX, H.E., FUJITA, R., HEINEMANN, D., LENIHAN, H.S., MADIN, E.M.P., PERRY, M.T., SELIG, E. R., SPALDING, M., STENECK, R., WATSON, R. A. Global Map of Human Impact on Marine Ecosystems. Science, v. 319, n. 5865, p. 948-952, 2008.

HALPERN, B.S., FRAZIER, M., AFFLERBACH, J., LOWNDES, J.S., MICHELI, F., O'HARA, C., SCARBOROUGH, C., SELKOE, K.A. Recent pace of change in human impact on the world's ocean. Scientific Reports v. 9, 11609, 2019. https://doi.org/10.1038/s41598-019-47201-9

HELSEL, S. Virtual Reality and Education. Educational Technology, v. 32, n. 5, p.38-42, 1992.

HOME, M., THOMPSON, E.M. The role of virtual reality in built environment education. Journal for Education in Built Environment, v. 3, n. 1., p. 5-24, 2008.

KATON, G.F. et al. Percepção de Ambientes Marinhos e Costeiros: uma visão de estudantes de um curso técnico em meio ambiente. Revista de Ensino de Biologia, n. 7, p. 2648-2460, 2014.

KAVANAGH, S., LUXTON-REILLY, A., WÜENSCHE, B., PLIMMER, B. Creating $360^{\circ}$ educational video: A case study. In: Proceedings of the 28th Australian Conference on Computer-Human Interaction. Launceston, Tasmania, Australia: Association for Computing Machinery (ACM), p. 34-39, 2016. https://doi.org/10.1145/3010915.3011001.

LINCOLN, Y.S; GUBA, E.G. Naturalistic inquiry. Londres, Sabe, 1985.

LU, S.-J., LIU, Y.-C. Integrating augmented reality technology to enhance children's learning in marine education. Journal of Environmental Education Research, v. 21, n. 4. p. 525-541, 2015.

MARTINHO, R.L; TALAMONI, B.L.J. Representações sobre meio ambiente de alunos da quarta série do Ensino Fundamental. Ciência \& Educação, v. 13, n. 1, p. 1-13, 2007.

MELO, R.S; CRISPIM, M.C; LIMA, E.R.V. O turismo em ambientes recifais: em busca da transição para a sustentabilidade. Caderno Virtual de Turismo, v. 5, n. 4, p. 34-42, 2005.

MENEGUETTE. C.L. Realidade Virtual e Experiencia do Espaço - Imersao, fenomenologia, tecnologia. PUC-SP. 2010. Disponivel em: https://sapientia.pucsp.br/bitstream/handle/18261/1/Lucas\%20Correia\%20Mene quette.pdf. Acesso em 10 ago 2019.

MIKROPOULOS, T., CHALKIDIS, A., KATSIKIS, A., KOSSIVAKI, P. Virtual realities in environmental education: the project LAKE. Education and Information Techonolgies, v.2., p.131-142, 1997. 
MORAES, R. Análise de Conteúdo. Revista Educação, Porto Alegre, v. 22, n. 37, p. 7-32, 1999.

MOSER, A.S., GREGÓRIO, A., PIRES, E.A.C.; MOREIRA, A.L.O.R. Concepções de ambiente e Educação Ambiental de professores: o padlet como uma ferramenta interativa. Revista Brasileira de Educação Ambiental (RevBEA), v. 15, n. $5, \quad$ p. $20-36, \quad 20$. https://doi.org/10.34024/revbea.2020.v15.10299

OLABUENAGA, J.I.R; ISPIZUA, M.A. La descodificación de la vida cotidiana: métodos de investigación cualitativa. Bilbao, Universidad de Deusto, 1989.

PALMINTIERI, S. Virtual Reality 360-degree video: An "empathy-generating machine" for conservation outreach? 2019. Disponível em https://news.mongabay.com/2019/04/virtual-reality-360-degree-video-anempathy-generating-machine-for-conservation-outreach/. Acesso em 05 ago 2020.

PEDRINI, A.G; COSTA, C; NEWTON, T; MANESCHY, F.S; SILVA, V.G; BERCHEZ, F; SPELTA, L; GHILARDI, N.P; ROBIM, M.J. Efeitos ambientais da visitação turística em áreas protegidas marinhas: estudo de caso na Piscina Natural Marinha, Parque Estadual da Ilha Anchieta, Ubatuba, São Paulo, Brasil. OLAM - Ciência e Tecnologia, v. 7, n. 1, p. 678-696, 2007.

PEDRINI, A.G; DE-PAULA, J. Educação Ambiental: Críticas e Propostas. In: PEDRINI, A. de G. (Org.) Educação Ambiental; Reflexões e Práticas Contemporâneas. Petrópolis: Vozes. 2011. p. 90-146.

PEDRINI, A.G.; BOCHNIAK, M. Percepção ambiental dos usuários da praia de Copacabana, cidade do Rio de Janeiro (RJ) sobre a problemática de resíduos sólidos. In: Congresso Nacional de Educação Ambiental, 3., Anais... p. 33-42, João Pessoa, 2013.

PIMENTEL, K.; TEIXEIRA, K. Virtual reality - through the new looking glass. 2.ed. New York, McGraw-Hill. 1995.

PETROSILLO, I; ZURLINI, G; CORLIANO, M.E; ZACCARELLI, N; DADAMO, M. Tourist perception of recreational environment and management in a marine protected area. Landscape and Urban Planning, v. 79, p. 29-37, 2007.

RAJECKI, D.W. Attitudes, themes and advances. Sunderland: Sinauer Associates. 1982. 354p.

RIBEIRO, E.N.; ALMEIDA, F.R.; OLIVEIRA, M.C. Ações de sensibilização na implementação da coleta seletiva solidária em um campus universitário. Revista Brasileira de Educação Ambiental (RevBEA), v. 15, n. 5, p. 124-141, 2020. https://doi.org/10.34024/revbea.2020.v15.10633

ROLIM, A.F; RODRIGUES, F.C.P; GADIG, B.F.O. Peixes de Recife Rochoso Estaçao ecologica de tupinambas. Sao Paulo. 2017. 79 p. 
ROUSSOU, M. Learning by doing and learning through play: an exploration of interactivity in virtual environments for children. Computers in Entertainment (CIE), v.2, n.1, p. 10, 2004.

SAVIETTO, F.S; KATON, F.G; TOWATA, N; BERCHEZ, S.A.F; URSI, S. Ambientes marinhos e costeiros: qual a percepção de estudantes de escolas do litoral norte de São Paulo?. Revista da SBEnBio, V Enebio e II Erebio Regional 1, n. 7, p. 6746-6757, 2014.

SILVA, A.N. Análise da divulgação de temas ambientais nas mídias sociais do jornal A Tribuna de Santos, litoral de São Paulo. UNISANTA. Anais do Encontro Nacional de Pós-Graduação - ENPG. v. 6, p. 458-463, 2017.

SNELSON, C., HSU, Y. Educational 360-Degree Videos in Virtual Reality: a Scoping Review of the Emerging Research. Tech Trends, v. 64, p. 404-412, 2020. https://doi.org/10.1007/s11528-019-00474-3

TAYLOR, G.L., DISINGER, J.F. The potential role of virtual reality in environmental education. Journal of Environmental Education, v. 28, n. 3, p. 38-43, 1997.

TUAN, Yi-fu. Topofilia- Um estudo da percepção, atitudes e valores do meio ambiente. São Paulo: Difel. 1980. 288 p.

UZZELL, D. The psycho-spatial dimension of global environmental problems. Journal of Environmental Psychology, v. 20, p. 307-318, 2000.

WWF. Overshoot Day. 2019. https://www.wwf.org.br/overshootday.cfm (acesso 29 jul 2019)

ZABALA, A. The future of Brazilian seas. Nature Sustainability, v. 1, p. 611612, 2018. https://doi.org/10.1038/s41893-018-0180-3 